УДК 631.162:657.22:637

$10.17213 / 2075-2067-2020-6-163-171$

\title{
АНАЛИЗ РЕЙТИНГОВ ЭФФЕКТИВНОСТИ ЗАКУПОЧНЫХ СИСТЕМ РЕГИОНОВ РОССИИ
}

\author{
(C) 2020 г. Е. И. Зацаринная, Н. В. Чумакова ${ }^{* *}$, К. М. Голубев ${ }^{* * *}$ \\ *Российский экономический университет имени Г. В. Плеханова, г. Москва, Россия \\ "* Азово-Черноморский инженерный институт, \\ Донской государственный аграрный университет, г. Зерноград, Россия \\ *** ООО «ДИХАУС», г. Москва, Россия
}

Целью исследования является проведение анализа существующих методик оценки эффективности государственных закупок и формулирование предложений по совершенствованию применяемых индикаторов и критериев эффективности закупочных систем.

Методологическую базу исследования представляют общенаучные методы: обобщзение, анализ, сравнение, приемы систематизации и классификации.

Результаты исследования. Определена сущность эффективности государственных и муниципальных закупок, которая была рассмотрена как с точки зрения эффективности функиионирования всей закупочной системы, так и эффективности отдельного заказа. Также в ходе проведенного анализа различных индикаторов, применяемых в России и за рубежом, были определены основные недостатки существующей системы индикаторов в субъектах Российской Федераџии. Для усовершенствования качества используемых индикаторов предложено применить зарубежный опыт систем Организации экономического сотрудничества и Мирового банка по созданию комплексных показателей и сравнению результатов с международными стандартами. Даны рекомендации по разработке универсальных комплексных количественных и качественных показателей, оцениваюших эффективность закупочной системы, для всех регионов, а также предложены индикаторы, оцениваюшие вероятность неблагоприятных последствий для размещчения заказа.

Перспективу исследования составляет достижение одной из приоритетных изелей на сегодняшний день - повышение эффективности государственных и муниципальных закупок. Для этого необходимо разработать и внедрить в практику специальные индикаторы, которыми могли бы пользоваться как государственные и региональные власти для оценки эффективности их закупочных систем, так и заказчики.

Ключевые слова: эффективность; результативность; государственные закупки; индикаторы; критерии; регион.

\section{ANALYSIS OF PERFORMANCE RATINGS OF PURCHASING SYSTEMS IN RUSSIAN REGIONS}

\author{
(C) 2020 E. I. Zatsarinnaya*, N. V. Chumakova ${ }^{* *}$, K. M. Golubev ${ }^{* * *}$
}

"Plekhanov Russian University of Economics, Moscow, Russia

${ }^{* *}$ Azov-Black Sea Engineering Institute, Don State Agrarian University, Zernograd, Russia

*** The Limited Liability Company «diHouse», Moscow, Russia 
The purpose of the study is to analyze the existing methods for assessing the effectiveness of public procurement and formulate proposals for improving the indicators and criteria for the effectiveness of procurement systems.

The methodological basis of the research is represented by general scientific methods: generalization, analysis, comparison, methods of systematization and classification.

Research results. The essence of the effectiveness of state and municipal purchases was determined, which was considered both from the point of view of the effectiveness of the functioning of the entire procurement system, and the effectiveness of a separate order. Also, in the course of the analysis of various indicators used in Russia and abroad, the main shortcomings of the existing system of indicators in the constituent entities of the Russian Federation were identified. To improve the quality of the indicators used, it is proposed to apply the foreign experience of the systems of the Organization for Economic Cooperation and the World Bank in creating complex indicators and comparing the results with international standards. Recommendations are given for the development of universal complex quantitative and qualitative indicators that assess the effectiveness of the procurement system for all regions. And also proposed indicators that assess the likelihood of adverse consequences for placing an order.

The prospect of the study is the achievement of one of the priority goals for today - increasing the efficiency of state and municipal purchases. And for this, it is necessary to develop and introduce into practice special indicators that could be used by both state and regional authorities to assess the effectiveness of their procurement systems and customers.

Key words: efficiency; effectiveness; public procurement; indicators; criteria; region.

Введение. В данное время имеется огромное разнообразие различных индикаторов эффективности размещения государственных и муниципальных заказов, а также закупочных систем в целом. Однако большинство из существующих показателей оценивают лишь уже проведенные закупочные процедуры. Кроме того, многие индикаторы затрагивают эффективность лишь в сфере исполнения бюджета, обходя стороной какие-либо другие характеристики, например, сроки поставки или качество приобретенной продукции. Многие заказчики часто сталкиваются с проблемой отсутствия разработанных индикаторов, которые позволили бы проанализировать и спрогнозировать эффективность государственных и муниципальных заказов до их размещения, ведь такие показатели могут быть полезны как для обоснования действий заказчика, так и для обоснования предоставления необходимых бюджетных средств на осуществление закупок.

Параметры эффективности закупочных процедур. Такое понятие, как «эффективность», по отношению к государствен- ным закупкам можно трактовать по-разному, что показано на рисунке 1.

Следовательно, указанные выше понятия должны быть взаимосвязаны, так как, если вся закупочная система функционирует непродуктивно, то и эффективность размещения одиночных государственных и муниципальных заказов может снижаться. Однако нельзя не отметить, что эффективность для каждого объекта обычно определяется разными параметрами. К примеру, для отдельной государственной или муниципальной закупки таким параметром может являться тип контракта, а для всей закупочной системы это будет профессионализм работников, занимающихся закупочной деятельностью в каком-нибудь департаменте.

Если говорить про законодательную часть вопроса, то про эффективность государственных и муниципальных закупок несколько раз говорится в Законе №44-Ф3, что показано в таблице 1.

Отсюда можно сделать заключение о том, что с помощью действий должностных лиц оценивается эффективность государственных и муниципальных закупок, а эффектив- 
ность закупочных процедур является обязательной частью закупочной деятельности каждого заказчика.

С помощью проводимого мониторинга и аудита через обобщенную информацию органы государственной власти могут оценивать эффективность государственных и муниципальных закупок, а также давать свои рекомендации и советы по улучшению работы заказчиков и совершенствованию законодательной базы закупочной системы Российской Федерации, а именно Закона №44-Ф3.

Главная цель этих рекомендаций в том, чтобы повысить эффективность закупочных процедур.

Уже многие годы в мире пытаются усовершенствовать или разработать новые эффективные методы по оценке закупочных систем с помощью различных индикаторов.
Саму эффективность функционирования закупочной системы на государственном или муниципальном уровне можно оценить только по результатам ее работы за определенный временной промежуток.

Важной частью мониторинга любой системы, в том числе и закупочной, является разработка индикаторов.

Под понятием «индикатор» обычно подразумевается показатель, отражающий какие-либо изменения, вызванные действиями или программой, а также оценивающий деятельность какой-либо структуры, которая совершала эти действия или осуществляла программу.

В целом эффективность государственного и муниципального заказа может зависеть от большого количества факторов, часть из которых представлены на рисунке 2.

\section{Эффективность закупок в Законе №44-Ф3 [1]}

Таблица 1

\begin{tabular}{|l|l|}
\hline Статья Закона №44-Ф3 & \multicolumn{1}{|c|}{ Информация про эффективность закупок } \\
\hline ст. 12 & $\begin{array}{l}\text { Эффективность реализации закупочной деятельности - то, к } \\
\text { чему должны стремиться должностные лица заказчика. }\end{array}$ \\
\hline ч. 6 ст. 97 & $\begin{array}{l}\text { В сводном аналитическом отчете Федеральные органы } \\
\text { исполнительной власти дают свою оценку эффективности } \\
\text { закупок товаров, работ и услуг. }\end{array}$ \\
\hline ст. 98 & $\begin{array}{l}\text { Органы аудита проводят анализ и оценку эффективности } \\
\text { расходов на закупки. }\end{array}$ \\
\hline п. 3 ч. 3 ст. 102 & $\begin{array}{l}\text { Через оценку эффективности закупок может проходить } \\
\text { общественный контроль }\end{array}$ \\
\hline
\end{tabular}

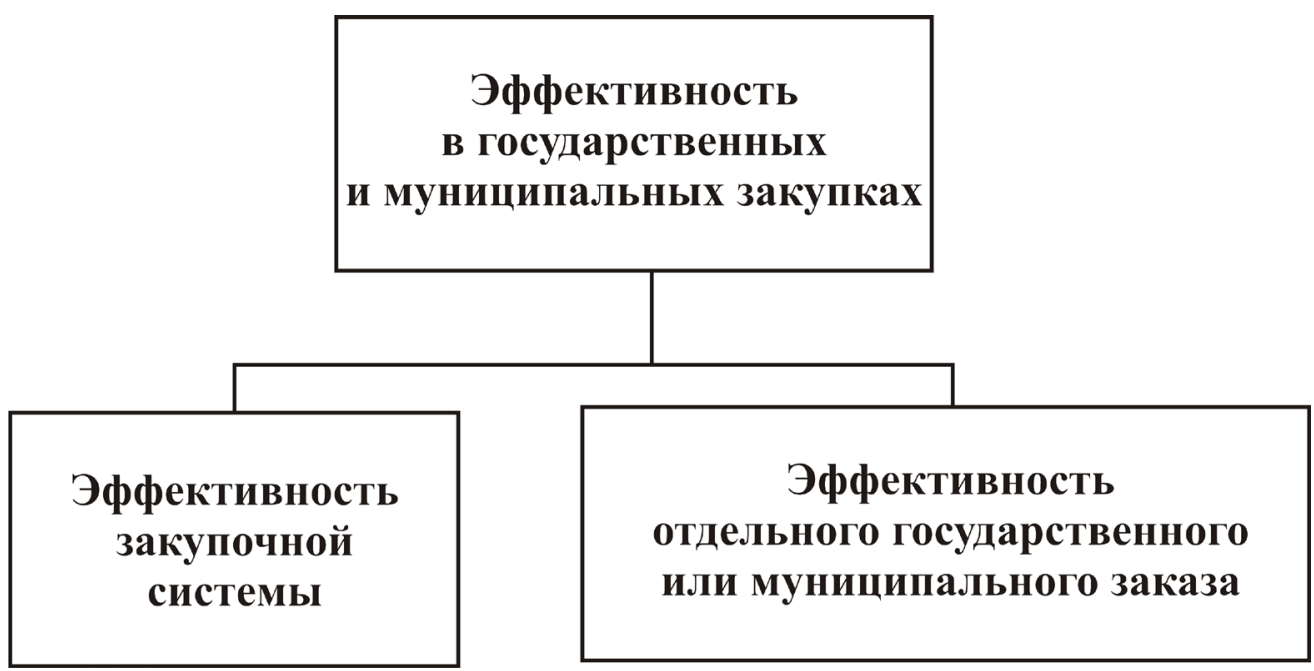

Рис. 1. Трактовки понятия эффективности государственных и муниципальных закупок [5] 


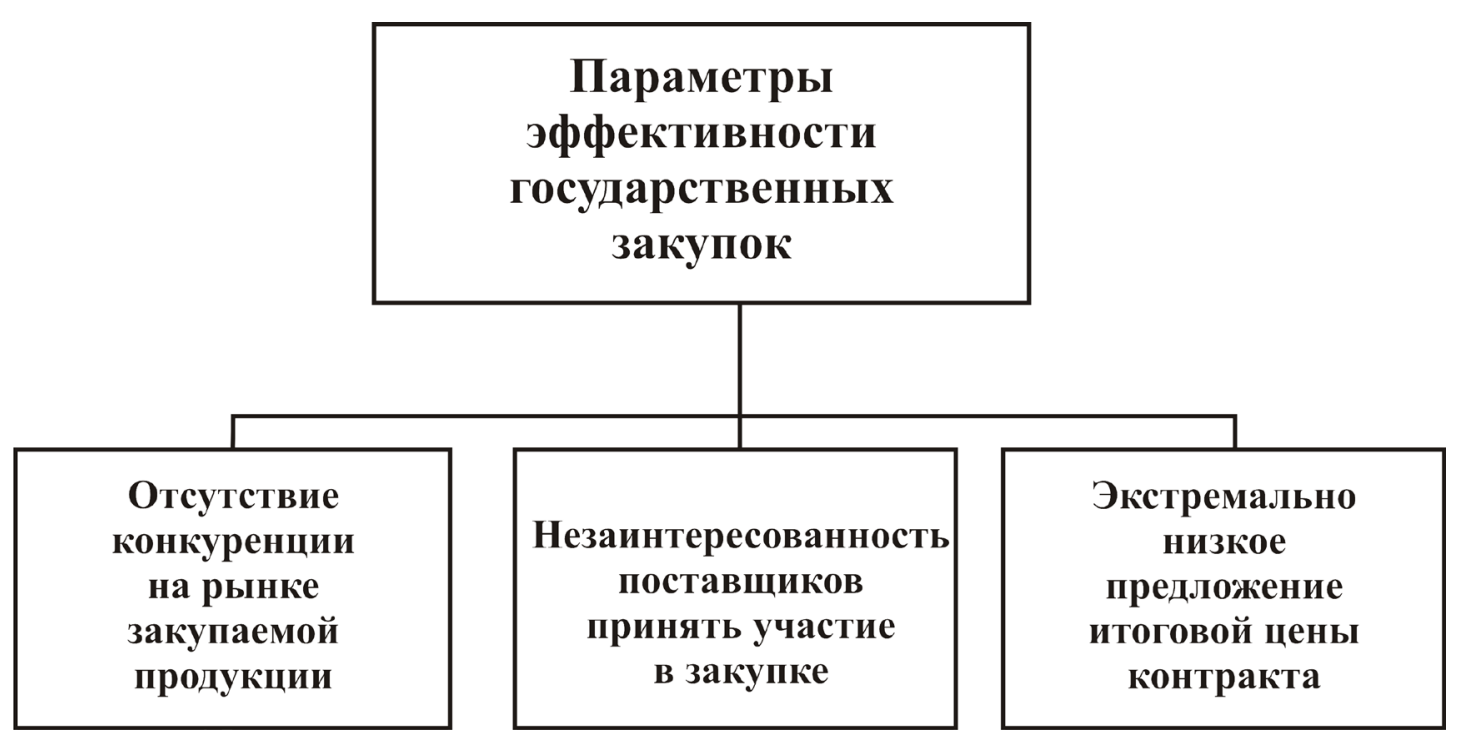

Рис. 2. Параметры эффективности размещения государственных и муниципальных заказов [5]

\section{Планирование}

Данный критерий оценивает, насколько точны были прогнозные потребности и затраты на их удовлетворение, что и за какие средства было закуплено по факту и что и на какие средства было запланировано. Соответственно, чем меньше разница между ними, тем эффективнее прошло планирование.

\section{Соблюдение конкуренции}

По мнению государственных органов, занимающихся мониторингом и аудитом, конкуренция также влияет на эффективность закупочной системы. В данном случае полученные результаты в ходе оценки количества торговых процедур, среднего количества заявок на закупки, доли закупок у ЕП сравнивают с аналогичными результатами по конкретному субъекту Российской Федерации или по всей стране.

\section{Экономия бюджетных денег или эффективность расходов}

В этом случае, как правило, оценивают экономию в процессе закупок, дополнительную экономию и экономию исполнения контрактов.

\section{Законность расходов}

Идет проверка соблюдения нормативно-правовой базы проведения закупок в Российской Федерации.

Рис. 3. Критерии эффективности закупочной системы [5] 
Все эти параметры тем или иным образом могут привести к поставке некачественной продукции или отмене размещения заказа, поэтому разработка инструментов, позволяющих минимизировать риски на протяжении всего закупочного процесса, крайне необходима.

Сначала стоит разобраться, на основании каких критериев закупочные системы и закупки в частности признаются эффективными. После анализа информации, представленной в Законе №44-Ф3, ПП РФ от 03.11.2015 г. №1193 «О мониторинге закупок» и Методологических рекомендаций Коллегии Счетной палаты РФ от 21.03.2014 г. №15К (961) «По проведению аудита», в виде схемы на рисунке 3 были представлены следующие основные критерии эффективности государственных и муниципальных закупок.

Также существуют различные классификации индикаторов эффективности закупочной системы в целом.

В настоящее время субъектами Российский Федерации применяется комплексный подход к оценке эффективности закупочных процедур, причем в рамках этого подхода опираются как на ценовые показатели, так и на индикаторы результативности закупок, а сам процесс оценки происходит поэтапно:

- на основе рекомендации Минэкономразвития РФ происходит оценка эффективности расходования бюджетных средств по каждой закупке;

- комплексно оценивается закупочная деятельность в регионе с помощью установленной системы индикаторов.

К примеру, в Мурманской области органы власти используют для оценки пять показателей, включая групповые, такие как конкурентность процедуры (доля бюджетных закупок в общем числе), соответствие закупки законодательству, качество планирования (разница между фактически проведенным закупками и планом), привлечение малого бизнеса (доля закупок среди субъектов малого бизнеса), дисциплина исполнения контрактов (количество дополнительных соглашений и прочее) [3].

В отличие от Мурманской области, в Санкт-Петербурге на данный момент происходит оценка эффективности закупочной деятельности с помощью 19 различных ин- дикаторов, утвержденных распоряжением Правительства Санкт-Петербурга от 9 февраля 2017 г. По окончанию расчета показателей их значения сравниваются с диапазоном возможных и рассчитывается итоговая оценка эффективности закупочных процедур в регионе. Каждому заказчику и органу исполнительной власти присваивается свой рейтинг, по которому делается вывод об эффективности его деятельности в сфере государственных закупок [2].

В России последние 5 лет существует популярный рейтинг эффективности и прозрачности закупочных систем. Цель данного проекта состоит в оценке и сравнении закупочной деятельности субъектов РФ по степени эффективности и прозрачности закупок. Решение о создании рейтинга было принято в 2015 г. на заседании Экспертного совета регионов по развитию контрактной системы Гильдии отечественных закупщиков. Ежегодно данный рейтинг рассчитывается в соответствии с методикой Экспертного совета регионов по развитию контрактной системы. В 2019 г. в рейтинге приняли участие 49 регионов по государственным закупкам и 35 регионов по муниципальным закупкам, a в рейтинге муниципальных закупок приняли участие 1026 муниципальных районов и городских округов. По каждому показателю определяются лидеры, а остальные регионы распределяются по группам в зависимости от отклонения от лидера.

В данном рейтинге оценка эффективности закупочных систем происходит по 8 индикаторам:

1) оценки:

- организационной структуры закупок;

- информационной инфраструктуры;

- профессионализма заказчиков и обеспеченности квалифицированными кадрами;

- осуществления закупочных процедур;

2) нормативной базы;

3) исполнения требований законодательства о закупках;

4) исполнения контрактов;

5) снятия административных барьеров и обеспечения доступности информации о системе закупок.

Каждый из указанных выше индикаторов является групповым и рассчитывается на основе множества других показателей. Это 
Лидеры рейтинга (государственные закупки) [6]

\begin{tabular}{|l|c|}
\hline \multicolumn{1}{|c|}{ Наименование региона } & $\begin{array}{c}\text { Количество номинаций } \\
\text { с тах значениями показателей }\end{array}$ \\
\hline Тюменская область & 5 \\
\hline Алтайский край & 3 \\
\hline Воронежская область & 2 \\
\hline Новосибирская область & 2 \\
\hline Ростовская область & 2 \\
\hline
\end{tabular}

позволяет точнее оценить эффективность закупочной системы региона в целом, так как во внимание принимается множество различных критериев, затрагивающих всегда аспекты сферы закупок в регионе. Данный рейтинг позволяет участникам в полной мере оценить эффективность своей деятельности и исправить отстающие неэффективные аспекты закупочной деятельности.

По рейтингу 2019 г. лидерами среди 49 регионов по эффективности государственных закупок стали следующие субъекты (табл. 2).

Остальные регионы набрали менее двух номинаций. Данный рейтинг используется регионами как дополнительный инструмент оценки эффективности закупочной деятельности.

По итогам рейтинга наиболее интересным будет рассмотреть опыт Тюменской области как лидера рейтинга по оценке эффективности закупочной деятельности в регионе. В данном субъекте эффективность оценивают с помощью шести критериев, включающих в себя различные индикаторы. Например, среди показателей эффективности закупок используются: удельный вес соответствующих конкурентных закупок в общем объеме закупок; доля несостоявшихся закупок; доля закупок, открытых аукционом в электронной форме; экономия, полученная по результатам закупок; показатели количества обоснованных и частично обоснованных жалоб и т.д. То есть видно, что в регионе используют индикаторы совершенно различного плана, как «денежные» и количественные показатели, так и качественные. Из-за подобного подхода к комплексной оценке эффективности закупочной системы региону удалось занять высокие позиции в рейтинге.
Во многом данная методика похожа на ту, которую используют составители рейтинга [2].

Заключение. Подводя итог проделанному анализу, мы пришли к выводу, что наиболее эффективной системой индикаторов в России сейчас является рейтинг Экспертного совета регионов по развитию контрактной системы. Их методология наиболее полно представляет каждый комплексный индикатор с подробным описанием их работы и способа расчета. Данную методологию следует рассмотреть для принятия на Федеральном уровне, чтобы регионы смогли по одной схеме и одним индикаторам отслеживать эффективность работы своих закупочных систем. При существовании одинаковых для всех регионов индикаторов и методологий будет легче находить лидеров по эффективности закупочных систем, что позволит другим регионам перенимать у них опыт.

Кроме того, рекомендуется законодательно закрепить больше критериев эффективности закупочной деятельности в нормативно-правовых документах, таких как Федеральный закон №44-Ф3, чтобы избежать значительного перекоса в сторону эффективности бюджетных расходов. Это позволит создать больше именно качественных показателей, которые затрагивали бы не менее важные стороны закупочного процесса.

Заказчикам предлагается ввести модель индикаторов, показывающих разные комбинации способов закупок с вероятностью наступления тех или иных неблагоприятных последствий. Эти индикаторы можно рассчитать с помощью критерия Сэвиджа или математического ожидания. 
Предложенные методологии и индикаторы должны помочь регионам усовершенствовать свою систему показателей эффективности закупочной системы и являются рабочим инструментом для решения различного рода системных проблем.

\section{Литература}

1. О контрактной системе в сфере закупок товаров, работ, услуг для обеспечения государственных и муниципальных нужд: Федеральный закон от 05.04.2013 г. №44-Ф3 [Электронный ресурс] / Консультант-плюс. - Режим доступа: http://www. consultant.ru.

2. Об утверждении Порядка оценки эффективности деятельности заказчиков при осуществлении закупок товаров, работ, услуг для обеспечения нужд Санкт-Петербурга: Распоряжение Правительства Санкт-Петербурга от 9 февраля 2017 г. №9-рп [Электронный ресурс] / Консультант-плюс. — Режим доступа: http://www.consultant.ru.

3. Об утверждении Методики оценки эффективности осуществления закупок товаров, работ, услуг для обеспечения нужд Тюменской области: Распоряжение Управления государственных закупок Тюменской области от 17 октября 2018 г. №002-р [Электронный ресурс] / Консультант-плюс. - Режим доступа: http://www.consultant.ru.

4. Методика комплексной системы оценки эффективности деятельности заказчиков Мурманской области в сфере закупок товаров, работ, услуг [Электронный ресурс] / Официальный сайт Правительства Мурманской области. - 2005-2020. - Режим доступа: https:/goszakaz.gov-murman.ru/ (Дата обращения: 02.11.2020).

5. Официальный сайт ООО «МЦФЭР» [Электронный ресурс]. - Режим доступа: https://www.pro-goszakaz.ru/article/103511qqq-19-m12-effektivnost-zakupok (Дата обращения: 02.11.2020).

6. Официальный сайт Общероссийской общественной организации «Гильдия отечественных закупщиков и специалистов по закупкам и продажам» [Электронный ресурс]. - Режим доступа: http://www.ooogos. ru/regions/rating/metodiki-raschyeta-kriteriev. php (Дата обращения: 02.11.2020).

\section{References}

1. O kontraktnoj sisteme v sfere zakupok tovarov, rabot, uslug dlja obespechenija gosudarstvennyh i municipal'nyh nuzhd: Federal'nyj zakon ot 05.04.2013 g. №44-FZ [On the contract system in the sphere of procurement of goods, works, and services for state and municipal needs: Federal law №44-FZ of 05.04.2013] [Jelektronnyj resurs] / Konsul'tant-pljus. URL: http://www.consultant.ru.

2. Ob utverzhdenii Porjadka ocenki jeffektivnosti dejatel'nosti zakazchikov pri osushhestvlenii zakupok tovarov, rabot, uslug dlja obespechenija nuzhd Sankt-Peterburga: Rasporjazhenie Pravitel'stva Sankt-Peterburga ot 9 fevralja 2017 g. №9-rp [On approval of the Procedure for evaluating the effectiveness of customers' activities when purchasing goods, works, and services to meet the needs of Saint Petersburg: Order of the government of Saint Petersburg №9-RP dated February 9, 2017] [Jelektronnyj resurs] / Konsul'tant-pljus. — URL: http:// www.consultant.ru.

3. Ob utverzhdenii Metodiki ocenki jeffektivnosti osushhestvlenija zakupok tovarov, rabot, uslug dlja obespechenija nuzhd Tjumenskoj oblasti: Rasporjazhenie Upravlenija gosudarstvennyh zakupok Tjumenskoj oblasti ot 17 oktjabrja 2018 g. №002-r [On approval of the Methodology for evaluating the effectiveness of procurement of goods, works, and services to meet the needs of the Tyumen region: Order of the public procurement Department of the Tyumen region dated October 17, 2018 №002-R] [Jelektronnyj resurs] / Konsul'tant-pljus. — URL: http://www. consultant.ru.

4. Metodika kompleksnoj sistemy ocenki jeffektivnosti dejatel'nosti zakazchikov Murmanskoj oblasti v sfere zakupok tovarov, rabot, uslug [Methodology of the integrated system for evaluating the effectiveness of customers of the Murmansk region in the field of procurement of goods, works, and services] [Jelektronnyj resurs]/ Oficial'nyj sajt Pravitel'stva Murmanskoj oblasti [Official website of the government of the Murmansk region]. - 2005-2020. URL: https://goszakaz.gov-murman.ru/ (Date accessed: 02.11.2020).

5. Oficial'nyj sajt OOO «MCFJeR» [Official website of LLC «MCFJeR»] [Jelektronnyj resurs]. - URL: https://www.pro-goszakaz. 
ru/article/103511-qqq-19-m12-effektivnost-zakupok (Date accessed: 02.11.2020).

6. Oficial'nyj sajt Obshherossijskoj obshhestvennoj organizacii «Gil'dija otechestvennyh zakupshhikov i specialistov po zakupkam i prodazham» [Official website of the all-Russian public organization «Guild of domestic buyers and specialists in procurement and sales»] [Jelektronnyj resurs]. — URL: http://www.ooogos. $\mathrm{ru} /$ regions/rating/metodiki-raschyeta-kriteriev. php (Date accessed: 02.11.2020).
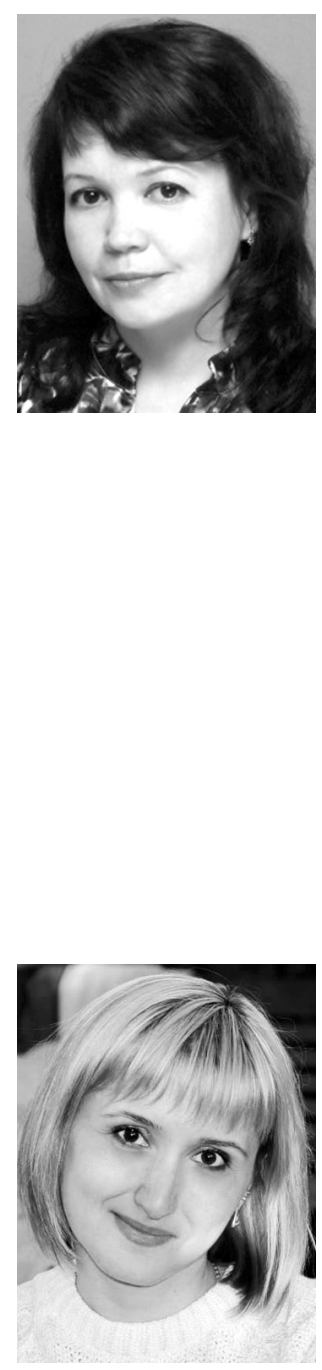

Зацаринная Елена Ивановна - кандидат экономических наук, доцент базовой кафедры финансового контроля, анализа и аудита Главного контрольного управления города Москвы Российского экономического университета имени Г. В. Плеханова.

Zatsarinnaya Elena Ivanovna - Candidate of Economic Sciences, Associate Professor of the Base Department Financial Control, Analysis and Audit, Main Control Department of Moscow, Plekhanov Russian University of Economics.

117997, г. Москва, Стремянный пер., 36 36 Stremyanny av., 117997, Moscow, Russia

E-mail: e29175z@yandex.ru

Чумакова Наталья Валерьевна - кандидат экономических наук, доцент, заведующая кафедрой бухгалтерского учета, анализа и аудита Азово-Черноморского инженерного института.

Chumakova Natalya Valeryevna - Candidate of Economic Sciences, Associate Professor, Head of the Department of Accounting, Analysis and Audit, Azov-Black Sea Engineering Institute of Don State Agrarian University.

347740, г. Зерноград, ул. Ленина, 21

21 Lenina st., 347740, Zernograd, Russia

E-mail: natalja_chumakova@rambler.ru 


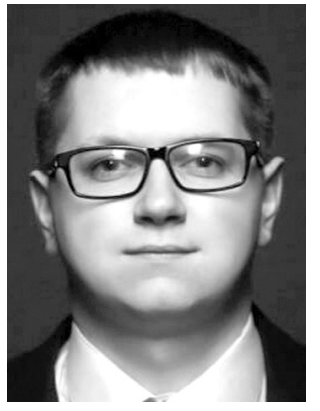

Голубев Кирилл Максимович - ассистент продакт-менеджера ООО «ДИХАУС», Департамент экосистемы Ксяоми.

Golubev Kirill Maksimovich - Assistant Product Manager «diHouse», Xiaomi Ecosystem Department.

111250 , г. Москва, пр-д Завода Серп и Молот, 6, к. 1

6 pr. Serp I Molot fact., 111250, Moscow, Russia

E-mail: makvell77777@gmail.com 